\title{
Use of Topical Nitric-Zinc Complex Solution to Treat Palmoplantar and Periungual Warts in a Pediatric Population
}

\author{
Aniza Giacaman (D) - Corinne Granger · Sonia Aladren · \\ Ana Bauzá - Bárbara Alomar Torrens · María Riutort Mercant • \\ Ana Martin-Santiago
}

Received: August 6, 2019 / Published online: October 4, 2019

(C) The Author(s) 2019

\section{ABSTRACT}

Introduction: Nitric-zinc complex solution (NZCS) is a topically applied solution containing nitric acid, zinc, copper, and organic acids that induce a painless caustic effect on "difficult-to-treat" warts, including palmoplantar and periungual locations. The objective of the present prospective clinical study was to describe the efficacy and tolerability of NZCS in the treatment of palmoplantar and periungual warts in children.

Methods: Eligible patients were immunocompetent children and adolescents, with at least one palmoplantar or periungual wart. NZCS was topically applied every 2 weeks in clinic. Efficacy was recorded by clinical evaluation, and acceptability assessments were measured using a visual analogue scale (VAS).

Results: Pediatric patients $(N=12)$ were equally distributed by gender, and the mean age

Enhanced Digital Features To view enhanced digital features for this article go to https://doi.org/10.6084/ m9.figshare.9873737.

A. Giacaman $(\bowtie)$ · A. Bauzá · B. Alomar Torrens ·

M. Riutort Mercant - A. Martin-Santiago

Dermatology Department, Hospital Universitari Son

Espases, Mallorca, Spain

e-mail: anizagiacaman@gmail.com

C. Granger · S. Aladren

Innovation and Development, ISDIN, Barcelona, Spain was $9.60 \pm 3.34$ years. The youngest patient was 4 years old. A total of 31 warts were identified: 24 periungual warts $(77.4 \%), 2$ palmar warts $(6.45 \%)$, and 5 plantar warts $(16.12 \%)$. We observed complete resolution in $83.9 \%$ of the warts treated with NZCS, achieving total cure considered as therapy success in $87.5 \%$ of periungual warts and $71 \%$ of palmoplantar warts, with a mean of 6.0 treatment sessions. The esthetic results evaluated by the investigator were considered excellent in $83.3 \%$ of cases and good in $16.7 \%$. In $100 \%$ of the completely resolved cases, no scars, erythema, hyperpigmentation, hypopigmentation, or hypertrophy in the area surrounding the treated warts were observed by the investigator. The esthetic results evaluated by the patients or parents/guardians were excellent. Pain and burning sensation were minimal and well tolerated. No clinically relevant adverse events were reported. Conclusion: NZCS was an effective treatment of warts in this pediatric population. The painlessness, simplicity, and twice-monthly dosing regimen of this treatment represents an advantage over standard approaches.

Funding: ISDIN.

Trial Registration: Retrospectively registered 6 September 2019, ISRCTN90862249.

Keywords: Children; Difficult to treat; Painless; Warts 


\section{INTRODUCTION}

Warts are one of the most common reasons for dermatology and primary care consults in children. Up to one-third of primary schoolchildren have warts, and an estimated $9.1-21.7 \%$ of dermatology referrals are for cutaneous wart treatment. Nonetheless, no definitive therapy to cure and prevent recurrences is available yet [1]. Several types of treatments, such as keratolytic, cryotherapy, lasers, antimitotic treatments, contact sensitizers, and intralesional injection of antigens have been used [2-4]. There is no evidence that one treatment is superior to others, and in many cases the treatment of viral warts requires a combination of therapies $[1,5]$. The choice of treatment for a patient should be guided by variables such as wart size, number of lesions, anatomic site, patient preference, cost, convenience, adverse effects, and operator experience. It is important to highlight that good communication between the patient, parents, and the dermatologist is an essential element for successful treatment in children. Unfortunately, the available treatments can be painful, and they can leave scars or induce hypo- or hyperpigmentation. Recurrence rates of warts in adults after any treatment range from $6 \%$ to $100 \%$ [5]. Nitric-zinc complex solution (NZCS) is a medical device already in use in adults, which consists of a topically applied solution of nitric acid, zinc, copper, and organic acids that induces a painless caustic effect on "difficult-to-treat" warts, including palmoplantar and periungual locations [6]. Little data was available on the use of NZCS in children and adolescents in clinical studies; therefore, the objective of the present study was to describe the efficacy and tolerability of NZCS in the treatment of palmoplantar and periungual warts in this population.

\section{METHODS}

Patients attending the outpatient dermatology clinic at Hospital Universitari Son Espases, Mallorca, Spain, for palmoplantar and periungual warts between 1 March 2018 and 31 August 2018 were prospectively recruited and followed up. Eligible patients were immunocompetent children and adolescents, with at least one palmoplantar or periungual wart suitable for topical treatment and who had not used any other topical treatment during the previous month. Patients' demographic data and clinical history, including the number, location and duration of warts, previous treatments, and cutaneous or systemic comorbidities, were recorded.

NZCS, commercially available as Verrutop ${ }^{\circledR}$ (medical device class II ISDIN Spain), was topically applied using a $30-\mu \mathrm{L}$ capillary tube on each lesion until the wart changed to a yellowish color. Patients received one NZCS application every 2 weeks, until the wart was resolved or until the investigator considered that no further treatment was required.

The efficacy and acceptability assessments were measured at an appointment 2 weeks after the last application of NZCS. The evaluation included wart clearance (fully clear, yes or no), wart size (measured in millimeters), physician's global satisfaction of the treatment (from $0=$ none to 3 = excellent, agreement with the treatment and outcomes), and esthetic results with a 4-point ordinal scale (from $0=$ poor results, indicating large scars or induration of treated area, to $4=$ excellent cosmetics results, indicating no scars or pigmentation changes). Patients indicated the level of pain and burning sensation during and after treatment $(0=$ no pain/burning to $10=$ intense pain/burning) and the esthetic results using a visual analogue scale (VAS) $\quad(0=$ unacceptable, with scarring; $100=$ excellent, no residual scar).

\section{Statistical Analysis}

A descriptive analysis was performed for all variables. Continuous variables were described as the number of valid cases, mean, median, standard deviation, and 25th and 75th percentile (P25-P75). Categorical variables were described for each category as absolute and relative frequency over the total valid values $(N)$. All analyses were performed on an intention-totreat basis. 
The ethics committee of Son Espases Hospital in Mallorca, Spain, approved the study on 27 February 2018 (CI-214-18), and the parents or guardians of each patient provided signed informed consent for their child's participation in the study. The study conformed with the Helsinki Declaration of 1964, as revised in 2013, concerning human and animal rights. The study was retrospectively registered with the ISRCTN registry, on 6 September 2019, with study ID ISRCTN90862249.

\section{RESULTS}

Patients $(N=12)$ were equally distributed by gender ( 6 girls and 6 boys), and the mean age was $9.60 \pm 3.34$ years. The youngest patient was 4 years old, and the oldest was 16 years old.

A total of 31 warts with a mean of 2.5 lesions per patient were detected (Table 1). In 11 of the 12 patients (91.7\%), it was the first episode. The time from onset of warts to the first visit was recorded in 10 patients: it ranged from 6.4 to 40.8 months, with a median of 12.6 months. Eight patients $(66.7 \%)$ had received previous

Table 1 Baseline characteristics and NZCS treatment sessions

\begin{tabular}{ll}
\hline Patients & $N=12$ \\
Sex & \\
Male & 6 \\
Female & 6 \\
Age, mean \pm SD & $9.6 \pm 3.34$ \\
Warts & $N=31$ \\
Number of warts per patient, mean \pm SD & $2.58 \pm 1.73$ \\
Type of wart, $n$ (\%) & \\
Periungual & $24(77.4 \%)$ \\
Palmar & $2(6.45 \%)$ \\
Plantar & $5(16.12 \%)$ \\
Number of treatment sessions with NZCS & \\
Mean \pm SD & $6.5 \pm 3.3$ \\
Median & 6.0 \\
\hline
\end{tabular}

treatments that had not resulted in complete clearance. Three of these patients (25\%) had been treated with cryotherapy, 2 (16.7\%) with salicylic acid, 3 (25\%) with combined treatments (cryotherapy plus salicylic acid or salicylic acid plus immunotherapy), and 4 patients had received no treatment before the first appointment with the dermatologist. The number of previous treatments by wart subtype is described in Table 2. The most frequent complaints about previous therapy were pain, with a mean score of $4 \pm 5.66$ for cryotherapy, and burning sensation, with a score of $6.50 \pm 4.95$ for cryotherapy and $6.5 \pm 0.71$ for salicylic acid.

We observed complete clearance in $83.9 \%$ of the warts treated with NZCS, achieving therapy success in $87.5 \%$ of periungual warts and $71 \%$ of palmoplantar warts, with a mean of $6.50 \pm 3.30$ sessions of treatment. There was a partial response in $16 \%$ of the warts after treatment with NZCS, with a percentage surface reduction close to $50 \%$. Investigator global satisfaction was graded as excellent in $25 \%$ of the patients and moderate in $75 \%$.

The esthetic results evaluated by the investigator were considered excellent in $83.3 \%$ of cases and good in $16.7 \%$. In all of the patients with complete resolution, no scars, erythema, hyperpigmentation, hypopigmentation, or hypertrophic scarring were observed by the

Table 2 Number of previous wart treatments

\begin{tabular}{ll}
\hline Number of previous treatments & $\boldsymbol{N = \mathbf { 2 4 } ( \mathbf { 1 0 0 } \% )}$ \\
\hline Periungual warts & \\
0 & $6(25 \%)$ \\
1 & $7(29.2 \%)$ \\
$\geq 2$ & $11(45.8 \%)$ \\
\hline Number of previous treatments & $\boldsymbol{N}=7(\mathbf{1 0 0} \%)$ \\
\hline Palmoplantar warts & \\
0 & $0(0 \%)$ \\
1 & $6(85.7 \%)$ \\
$\geq 2$ & $1(14.3 \%)$ \\
\hline
\end{tabular}




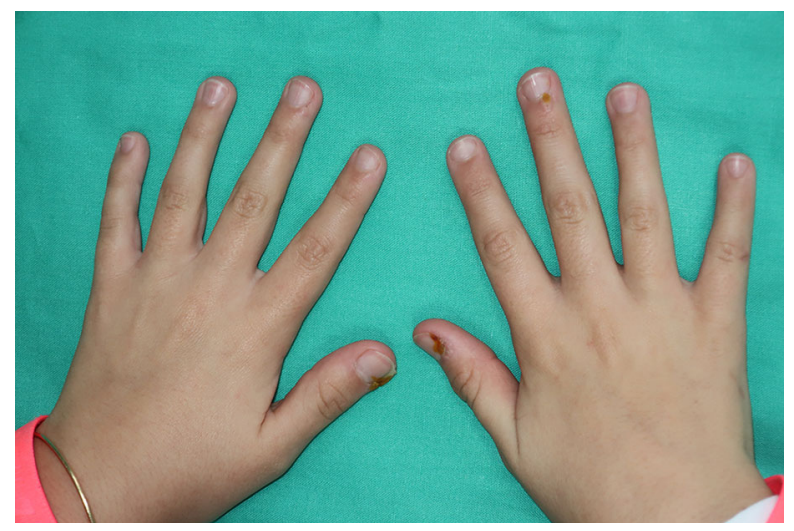

Fig. 1 An 11-year-old girl during the first session of treatment with NZCS. Note the change in color of the treated area. The informed consent included permission to use images of patients

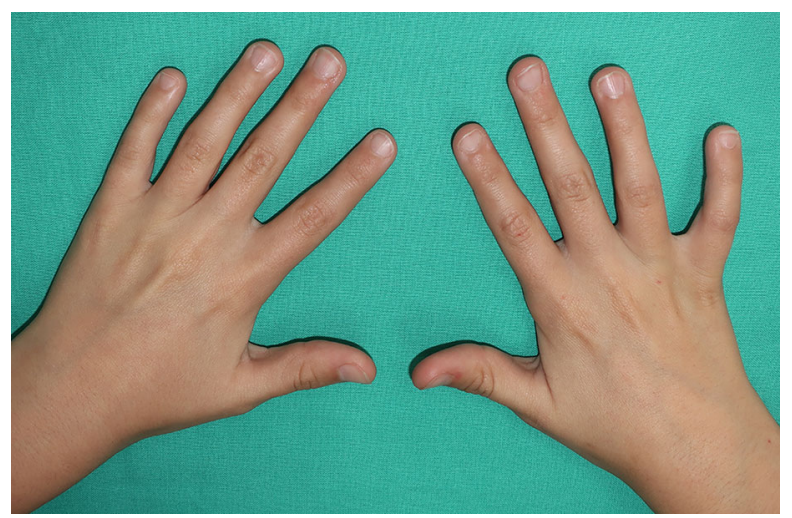

Fig. 2 The same patient 1 month after the fourth session, with complete resolution of the warts

investigator in the treated and surrounding areas (Figs. 1 and 2).

The esthetic results evaluated by the patients or parents/guardians were excellent, with a VAS score of $89.09 \pm 9.70$. Pain and burning sensation were well tolerated, with a score of $0.24 \pm 1.14$ and $2.49 \pm 3.09$, respectively, during treatment and $0.03 \pm 0.22$ and $2.05 \pm 2.84$ after treatment. No clinically relevant adverse events were reported.

\section{DISCUSSION}

Warts are superficial viral infections of the skin and are very common in children. They are caused by infection with the human papillomavirus (HPV). Transmission of HPV is very easy owing to its survival on the skin, fomites, and surfaces, and it can be transmitted from person to person and from one area of the body to another on the same person. Approximately $30 \%$ of children develop warts, and they are more common in those with atopic dermatitis [7]. Treating palmoplantar and periungual warts can be challenging. For this reason, a variety of treatments are used, often in combination.

Therapies for pediatric warts are characterized according to six major categories: destructive (salicylic acid, cryotherapy, cantharidin, podophyllotoxin, topical retinoids); immune stimulating (imiquimod, orally administered cimetidine, squaric acid, diphencyprone, intralesionally administered candida antigen); immune modulating (zinc, plerixafor); vascular destructive (pulsed dye laser); irritant (duct tape); photodynamic therapy and nitric oxide releasing $[7,8]$. Therapies for children must be safe and preferably painless; this is very important because two-thirds of warts will resolve without treatment within 2 years [1]. The much lower scores for pain and burning sensation that were reported with NZCS use in this study (mean pain score, 0.24; mean burning score, 2.49) than for previous treatments (mean pain score of 4 for cryotherapy; mean burning score of 6.50 for cryotherapy and for salicylic acid) indicate that this is a more comfortable approach for children.

Nitric-zinc complex solution is an aqueous solution, commercially available, containing organic acids (lactic, oxalic, and acetic acid at $8.6 \%$ each), small amounts of metallic ions (zinc and copper salts), and 65\% nitric acid as the leading compound with a caustic effect that causes "mummification", protein denaturation, and coagulation of the wart. NZCS has been useful in the treatment of palmoplantar and genital warts in adults, as reported in previous publications $[5,6,9,10]$; we are now able to provide data on its use in a pediatric population. The strengths of the study are that it provides new data on this treatment in a pediatric population, in a prospective study design; limitations include the small sample size, singlecenter design, and absence of a control group, 
although some data were available on tolerability (pain/burning) in patients who had had different previous treatments.

In this study we demonstrate the efficacy and excellent tolerability of NZCS in pediatric patients with palmoplantar and periungual warts known as "difficult-to-treat" warts due to the location, with less pain and discomfort than previous treatments. According to our results, NZCS was useful in a pediatric population with viral warts including cases that had been resistant to previous treatment, from 4 years old. The painless nature of the technique, the simplicity of administration in the clinic, and the twice-monthly dosing regimen represent an advantage over other existing treatments. More studies are needed to evaluate the rates of recurrence of viral warts after treatment with NZCS in children and adolescents as in adults.

\section{CONCLUSIONS}

In a pediatric population with palmoplantar and periungual warts, NZCS resulted in complete wart clearance in $83.9 \%$ and had excellent cosmetic effects, with extremely low discomfort levels, and represents a good treatment option for this population.

\section{ACKNOWLEDGEMENTS}

We thank the patients for their participation in this study.

Funding. ISDIN funded the costs of data analysis and the journal's Rapid Service Fee.

Editorial Assistance. Editorial assistance in the preparation of this article was provided by Jane Marshall, a freelance medical writer, editor, and translator. This assistance was funded by ISDIN.

Authorship. All named authors meet the International Committee of Medical Journal Editors (ICMJE) criteria for authorship for this article, take responsibility for the integrity of the work as a whole, and have given their approval for this version to be published.

Authorship Contributions. AG and AMS performed the research. SA, CG, and AMS designed the research study. AMS and SA analyzed the data. AG, AMS, CG, and SA wrote the paper.

Disclosures. Corinne Granger is an employee of ISDIN. Sonia Aladren is an employee of ISDIN. Aniza Giacaman, Ana Bauzá, Bárbara Alomar Torrens, María Riutort Mercant, and Ana Martin-Santiago have nothing to disclose.

Compliance with Ethics Guidelines. The ethics committee of Son Espases Hospital in Mallorca, Spain, approved the study on 27 February 2018 (CI-214-18), and the parents or guardians of each patient provided signed informed consent for their child's participation in the study. The study conformed with the Helsinki Declaration of 1964, as revised in 2013, concerning human and animal rights. The study was retrospectively registered with the ISRCTN registry, on 6 September 2019, with study ID ISRCTN90862249.

Data Availability. The datasets generated and analyzed during the current study are available from the corresponding author on reasonable request.

Open Access. This article is distributed under the terms of the Creative Commons Attribution-NonCommercial 4.0 International License (http://creativecommons.org/licenses/ by-nc/4.0/), which permits any noncommercial use, distribution, and reproduction in any medium, provided you give appropriate credit to the original author(s) and the source, provide a link to the Creative Commons license, and indicate if changes were made.

\section{REFERENCES}

1. Boull C, Groth D. Update: treatment of cutaneous viral warts in children. Pediatr Dermatol. 2011;28:217-29. 
2. Torrelo A. What's new in the treatment of viral warts in children. Pediatr Dermatol. 2002;19:191-9.

3. Jakhar D, Kaur I, Misri R. Intralesional vitamin D3 in periungual warts. J Am Acad Dermatol. 2019;80:e111-2.

4. Kimura U, Takeuchi K, Kinoshita A, Takamori K, Suga Y. Long-pulsed 1064-nm neodymium:yttriumaluminum-garnet laser treatment for refractory warts on hands and feet. J Dermatol. 2014;41:252-7.

5. Ciccarese G, Drago F, Granger C, Parodi A. Efficacy assessment of a topically applied nitric-zinc complex solution for the treatment of external anogenital warts in 100 patients. Dermatol Ther (Heidelb). 2019;9:327-35.

6. Cusini M, Micali G, Lacarrubba F, Puviani M, Barcella A, Milani M. Efficacy and tolerability of nitric-zinc complex in the treatment of external genital warts and "difficult-to-treat" warts: a "proof of concept", prospective, multicentre, open study. G Ital Dermatol Venereol. 2015;150:643-8.

7. Silverberg NB. Pediatric warts: update on interventions. Cutis. 2019;103:26-30, E2-E4.

8. Witchey DJ, Witchey NB, Roth-Kauffman MM, Kauffman MK. Plantar warts: epidemiology, pathophysiology, and clinical management. J Am Osteopath Assoc. 2018;1(118):92-105.

9. Rozas-Muñoz E, Mir-Bonafé J, Piquero-Casals J. Refractory warts successfully treated with a nitric-zinc complex solution. J Dermatol. 2019;46:e250-1.

10. Janniger CK, Schwartz RA. Efficacy and tolerability of a new topical nitric-zinc preparation for "difficult-to-treat" warts. Dermatol Ther. 2017. https:// doi.org/10.1111/dth.12456. 